\title{
Near infrared monitoring of mineralisation of liquid dairy manure in agricultural soils
}

\author{
Giovanni Cabassi, ${ }^{a}$ Pietro Marino Gallina, ${ }^{b}$ Stefania Barzaghi, ${ }^{a}$ Tiziana M.P. Cattaneo ${ }^{\mathrm{a},{ }^{*}}$ and Luca Bechini ${ }^{\mathrm{b}}$ \\ ${ }^{a}$ Agricultural Research Centre-Research Centre for Fodder Crops and Dairy Production (CRA-FLC), Via A. Lombardo 11, 26900 Lodi, Italy. \\ E-mail: tiziana.cattaneodentecra.it \\ ${ }^{\text {b}}$ Department of Crop Science, Section of Agronomy, University of Milan, Italy
}

\begin{abstract}
Liquid dairy manure is a major organic input to cultivated soils. Therefore, a method for monitoring the mineralisation of slurries should be a useful tool for managing soil fertilisation. In order to examine whether the biodegradation of cattle sludge can be monitored by near infrared (NIR) spectroscopy, soil samples from a laboratory incubation experiment were analysed using this rapid and inexpensive method. Five different cattle slurries were added to three soils with increasing clay content in such an amount as to give $130 \mathrm{ppm}$ of total nitrogen. The resulting 18 experimental treatments (three control soils and 15 soil-slurry combinations) were incubated for 180 days under optimal temperature and soil water content. Each treatment was sampled at 0, 2, 8, 12, 16, 21, 29, 41, 72, 121 and 180 days: the respired $\mathrm{CO}_{2}$ was captured in alkali traps and mineral $\mathrm{N}$ was extracted using $1 \mathrm{M} \mathrm{KCl}$. Three replicates of each sampling were analysed individually. The resulting 648 samples, air dried and ground at $0.5 \mathrm{~mm}$, were analysed by NIR spectroscopy using an Antaris (Thermo Nicolet) Fourier transform-NIR spectrometer. Although the slurries and soil mineralised carbon represent only a very small part of the total soil organic carbon, the mineralisation of carbon can be clearly monitored by NIR spectroscopy in both amended and unamended soils. Whereas $\mathrm{NO}_{3}-\mathrm{N}$ evolution was difficult to predict using $\mathrm{NIR}$ data, the results for $\mathrm{NH}_{4}-\mathrm{N}$ were more encouraging. Using measurements of $\mathrm{CO}_{2}-\mathrm{C}$ respired, a two-pool mineralisation model was developed and the simulated concentration of carbon pools in the soils were used for the development of NIR equations. The results obtained in this work have demonstrated that NIR is a useful tool for monitoring the carbon mineralisation process when cattle sludge is incorporated into agricultural soils.
\end{abstract}

Keywords: soil, organic matter, liquid dairy manure, mineralisation, microbial respiration, ammonium

\section{Introduction}

Knowledge of the dynamics of manure biodegradation is a basic requirement in order to take the greatest possible advantage of its nutrient content for crop growth and to minimise adverse environmental effects, mainly on groundwater. ${ }^{1}$ Furthermore, this knowledge can assist in making a better choice regarding the rate of mineral nitrogen fertilisers for side-dress applications. Nevertheless, the assessment of the biochemical quality of cattle liquid manures in soil is very unusual in agricultural practice, due to the absence of an easy and low-cost analytical technique available for its measurement, due to high costs and the time required for analyses.

Although organic carbon added to soil with liquid cattle manure represents only a small fraction of total soil carbon, both organic matter added to soil and its interactions (mainly with clayl can affect the reflection of radiation from the soil in the near infrared (NIR) region. Clay content is the most influential parameter in organic matter mineralisation. The adsorption of proteins and other organic compounds and their subsequent protection from decomposition has been known for many years. Clay minerals with a large surface area are capable of adsorbing organics and enzymes involved in organic matter decomposition, protecting them from hydrolytic attacks and reducing the availability of catalytic sites. $^{2}$

A relevant problem, when using NIR spectroscopy for studying the biodegradation of organic materials in soils, is the lack of analytical techniques for direct measurement ${ }^{3}$ of native substances and of products of decomposition, leading to lower 
Table 1. Composition of liquid dairy manure used in the mineralisation experiment.

\begin{tabular}{|c|c|c|c|c|c|c|c|c|c|}
\hline Manure & $\begin{array}{c}\text { Dry } \\
\text { matter } \\
(\%)\end{array}$ & $\begin{array}{l}\text { Ash } \\
\left.\text { [g } 100 \mathrm{~g}^{-1}\right]\end{array}$ & $\begin{array}{l}\text { Total N } \\
\text { (mg N g }{ }^{-1} \text { ) }\end{array}$ & $\begin{array}{c}\mathrm{NH}_{4}-\mathrm{N} \\
\text { ( } \mathrm{mg} \mathrm{Ng}^{-1} \text { ) }\end{array}$ & $\mathrm{pH}$ & $\begin{array}{l}\text { Electrical } \\
\text { conductivity } \\
\left.\text { (m } \mathrm{m} \mathrm{cm}^{-1}\right]\end{array}$ & $\begin{array}{l}\text { Total C } \\
\text { (g } 100 \mathrm{~g}^{-1} \\
\text { dry } \\
\text { matter) }\end{array}$ & $\begin{array}{l}\text { Total } \mathrm{P} \\
\text { (mg P g } \\
\text { dry } \\
\text { matter) }\end{array}$ & $\begin{array}{c}\text { Total } \mathrm{K} \\
\text { (mg K g }^{-1} \\
\text { dry } \\
\text { matter) }\end{array}$ \\
\hline 1 & 8.01 & 20.48 & 3.89 & 2.13 & 7.5 & 3.66 & 38.58 & 7.04 & 2.65 \\
\hline 2 & 10.25 & 21.82 & 2.68 & 0.9 & 7.43 & 1.6 & 39.34 & 4.79 & 1.33 \\
\hline 3 & 11.71 & 15.66 & 4.54 & 1.56 & 7.17 & 2.47 & 41.24 & 5.69 & 1.64 \\
\hline 4 & 4.85 & 25.05 & 3.65 & 1.81 & 7.5 & 5.16 & 36.68 & 10.85 & 4.36 \\
\hline 5 & 4.59 & nd & 2.59 & 1.08 & nd & nd & 39.43 & nd & nd \\
\hline
\end{tabular}

accuracy of reference values and, thus, of NIR calibrations. As proposed by Hartmann, ${ }^{4}$ when data based on isotopic tracing of organic carbon sources are not available, the use of models based on homogeneous carbon fractions can be useful.

The aims of this work were: (i) to test the ability of NIR spectroscopy in measuring soil carbon and nitrogen dynamics when dairy slurries are added and (ii) to evaluate NIR spectroscopy as a tool to link conceptual soil organic matter pools with easy and rapid measurement of soils in predicting the degradation of added organic materials.

The research was focused on monitoring carbon and nitrogen dynamics in three soils differing mainly in clay content. On the basis of poor preliminary results (data not shown) made using global models, soils were monitored one by one, performing chemometric analyses [principal component analysis (PCA) and partial least squares (PLS)] on each soil separately: in this way, all the spectral variations used in building up the chemometric models arise from both the organic matter degradation and its interaction with the same mineralogical matrix. All the possible correlations with spectral features other than those of the easily mineralisable compounds are avoided.

The soil organic matter pools were estimated using a mineralisation simulation model in order to foresee these dynamics at laboratory level. ${ }^{5}$ Reeves and Van Kessel ${ }^{6}$ investigated the carbon and nitrogen mineralisation of different manure on the same soil and showed the feasibility of this kind of study. The evolved $\mathrm{CO}_{2}$ was used by these authors as the parameter to be predicted, whereas here, the remaining carbon in soil was used as a calibration variable.

As extensively reviewed by Malley, ${ }^{7}$ once calibrated, NIR spectroscopy could be a rapid and inexpensive method and, therefore, it is highly regarded as a technique for routine soil analysis.

This work has demonstrated that NIR could be useful not only for the study of litter and green manure ${ }^{8-10}$ decomposition but also in the biodegradation of cattle slurry in soil.

\section{Materials and methods Incubation experiment}

Table 1 reports the characteristics of the five liquid dairy manures selected as representative by multivariate analysis from a set of 101 manures described by De Ferrari. ${ }^{11}$ These manures were a mixture of urine, faeces and bedding materials of dairy cattle stored for several weeks in tanks on a farm.

In order to quantify the effect of soil texture on sludge mineralisation, the five sludges were mixed with three different soils characterised by: (i) increasing clay content $\left(100,210\right.$ and $\left.340 \mathrm{~g} \mathrm{~kg}^{-1}\right)$, (ii) similar organic matter content, (iii) similar $\mathrm{C} / \mathrm{N}$ ratios and (iv) similar $\mathrm{pH}$. Sub-acidic $\mathrm{pH}$ conditions prevented ammonia volatilisation during the experiments. The composition of the three soils is given in Table 2.

Eighteen treatments were established, 15 of which resulted from the combination of the five manures with the three soils, plus three unmanured soils. The "nursery" experimental design described by Thuries et al. ${ }^{13}$ was adopted.

Six hundred and forty-eight experimental units were established to allow three replicates for each treatment and 12 destructive samplings over 180 days of incubation.

Table 2. Characterisation of the three soils used in the mineralisation experiment.

\begin{tabular}{|c|c|c|c|c|c|c|c|c|c|}
\hline Soil & $\mathrm{pH}$ & $\begin{array}{c}\text { C org } \\
\left(\mathrm{mg} \mathrm{kg}^{-1}\right)\end{array}$ & $\begin{array}{l}\text { Total N } \\
\left(\mathrm{g} \mathrm{kg}^{-1}\right)\end{array}$ & $\mathrm{C} / \mathrm{N}$ & 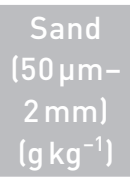 & $\begin{array}{c}\text { Silt } \\
(20-50 \mu \mathrm{m}) \\
\left(\mathrm{g} \mathrm{kg}^{-1}\right)\end{array}$ & $\begin{array}{c}\text { Silt } \\
(2-20 \mu \mathrm{m}) \\
\left(\mathrm{g} \mathrm{kg}^{-1}\right)\end{array}$ & $\begin{array}{l}\text { Total silt } \\
(2-50 \mu \mathrm{m})\end{array}$ & $\begin{array}{c}\text { Clay } \\
(<2 \mu \mathrm{m})\end{array}$ \\
\hline 1 & 6.54 & 13960 & 1.47 & 9.5 & 506 & 172 & 219 & 391 & 102 \\
\hline 2 & 6.74 & 14870 & 1.66 & 8.98 & 437 & 106 & 248 & 354 & 209 \\
\hline 3 & 6.61 & 18030 & 1.84 & 9.8 & 102 & 139 & 422 & 561 & 337 \\
\hline
\end{tabular}


Experimental units were constituted using $100 \mathrm{~mL}$ plastic bottles filled with an amount of wet soil corresponding to $60 \mathrm{~g}$ of soil dry weight. In the case of manured soils, the amount of manure required to produce $130 \mathrm{mg} \mathrm{kg}^{-1}$ dry soil was added. This rate corresponds to ca $600 \mathrm{~kg} \mathrm{Nha}^{-1}$ assuming a soil bulk density of $1.5 \mathrm{mg} \mathrm{m}^{-3}$ and a depth of $0.3 \mathrm{~m}$. Then, the corresponding addition of $C$ to soils was equal to 1031, 1640, 1382, 633, and $908 \mathrm{mg} \mathrm{kg}^{-1}$ dry soil for slurries 1, 2, 3, 4 and 5, respectively.

Incubation was carried out at $25^{\circ} \mathrm{C}$ and the soil water content was maintained at $\psi_{-50}$, where $\psi_{-50}$ is the volumetric soil water content at a water potential of $-50 \mathrm{kPa}$.

Before the experiment, manures were homogenised using an Ultra-Turrax homogeniser (IKA, Germany) equipped with a S25N-25G dispersing tool at a particle size lower than $50 \mu \mathrm{m}$ and the three soils were pre-incubated at $25^{\circ} \mathrm{C}$ for seven days at a water content of $0.75 \psi_{-50}$; this pre-incubation allowed the mineralisation of labile organic matter still present in soils.

Sampling was done at 0,2, 4, 8, 12, 16, 21, 29, 41, 75, 121 and 181 days from the start of incubation. At each sampling date, three replicates of each treatment were destroyed as a consequence of the analytical methods adopted and the replicates for the successive sampling date, taken from the nursery, were stored in individual sealed glass jars containing alkali traps $(20 \mathrm{~mL}$ of $\mathrm{NaOH} 0.5 \mathrm{M})$ for respiration measurements. The trapped $\mathrm{C}_{\mathrm{CO}_{2}}$, arising from biological respiration, was analysed during each incubation interval $(11$ intervals) by back-titration. The cumulative respiration for each treatment ( $\mathrm{g} \mathrm{C}_{\mathrm{CO}_{2}} \mathrm{~g} \mathrm{C}^{-1}$ added) was calculated as the sum of the titrated $\mathrm{C}_{\mathrm{CO}_{2}}$ relative to each incubation interval.

Mineral $\mathrm{N}$ was measured at each sampling date (12 times) on an aliquot of soil from each experimental unit; samples were extracted with $\mathrm{KCl} 1 \mathrm{M}$ (ratio 1:5). Concentrations of both $\mathrm{NH}_{4}-\mathrm{N}$ and $\mathrm{NO}_{3}-\mathrm{N}$ of the $\mathrm{KCl}$ extracts were determined by flow injection analysis and spectrometric detection. Analysis of $\mathrm{NH}_{4}-\mathrm{N}$ was done by the gas semi-permeable membrane method using a FlAstar 500 Analyzer (Foss, Denmark) according to the ISO 11732:1997 procedure [Determination of ammonium nitrogen by flow analysis (CFA and FIA) and spectrometric detection]. Analysis of $\mathrm{NO}_{3}-\mathrm{N}$ was done by the sulphanilamide-naphtylethylendiamine dihydrocloride method, after preliminary reduction of $\mathrm{NO}_{3}$ - to $\mathrm{NO}_{2}$ - by a copper-cadmium reductor column using a FIAstar 500 Analyzer (Foss, Denmark), according to the ISO 13395:1996 procedure [Determination of nitrite nitrogen and nitrate nitrogen and the sum of both by flow analysis (CFA and FIA) and spectrometric detection]. The aliquot of remaining soil in each pot was air dried at $40^{\circ} \mathrm{C}$ for two days and stored until NIR analysis.

\section{Mathematical model of organic carbon mineralisation}

A simple first order kinetics model with two pools of organic matter ${ }^{12}$ was fitted to measured respired $\mathrm{CO}_{2}-\mathrm{C}$ to simulate biological respiration of soils:

$$
\hat{C}_{\min }(t)=\left[C_{S}-C_{S} \exp \left(-K_{S} t\right)\right]+\left[C_{L}-C_{L} \exp \left(-K_{L} t\right)\right]
$$

where:

$\hat{\mathrm{C}}_{\text {min }}(t)\left(\mathrm{mg} \mathrm{C} \mathrm{kg}^{-1}\right.$ soil $)=$ the estimate of potentially mineralisable carbon at time $t$;

$C_{L}\left(\mathrm{mg} \mathrm{C} \mathrm{kg}^{-1}\right.$ soil $=$ the potentially mineralisable labile carbon pool;

$\mathrm{C}_{\mathrm{S}}\left(\mathrm{mgC} \mathrm{kg}^{-1}\right.$ soil) $=$ the potentially mineralisable resistant carbon pool;

$K_{L}\left(\right.$ day $\left.^{-1}\right)=$ decomposition constant of the labile pool, slurry dependent;

$\mathrm{K}_{\mathrm{S}}\left(\right.$ day $\left.^{-1}\right)=$ decomposition constant of the stable pool, soil dependent;

$t$ (days) $=$ time since the start of the incubation.

The model was built up assuming that:

the inert $C\left(C_{l}\right)$-defined as: total organic $C-\left(C_{S}+C_{L}\right)$-was not reactive on this temporal scale;

the carbon in unmanured soil was made up from only $\mathrm{C}_{\mathrm{S}}$ and inert $\mathrm{C}_{\mid}$;

the carbon in sludge consisted of $\mathrm{C}_{\mathrm{S}}+\mathrm{C}_{\mathrm{L}}$, and a small aliquot of $\mathrm{C}_{\text {. }}$.

Therefore, one $K_{L}$ for each sludge and three $K_{S}$, one for each soil, were estimated.

The mineralisation model was fitted by minimising the sum of the squared differences between measured and calculated C losses using the Excel Solver (Microsoft Excel, 2003, USA). All the simulated values were in very good agreement with the measurements: the relative root mean square error was only $2.6 \%$. In general, the model properly reproduced the observed $\mathrm{CO}_{2}-\mathrm{C}$ dynamics for all soil and manure combinations with a fast release between days 15 to 20 and a slower release thereafter. Table 3 shows the parameters optimised by the model. The decrease in size of the labile $\left[\mathrm{C}_{S}(t)\right]$ and resistant $\left[\mathrm{C}_{L}(t)\right]$ pool was estimated at each sampling date according to the following equations:

$$
\begin{aligned}
& C_{L}(t)=C_{L}-C_{L} \exp \left(-K_{L} t\right) \\
& C_{S}(t)=C_{S}-C_{S} \exp \left(-K_{S} t\right) .
\end{aligned}
$$

\section{NIR spectroscopy}

NIR analyses were performed on the air dried soils after grinding through a $0.5 \mathrm{~mm}$ sieve. Spectra were acquired in diffuse reflectance using an Antaris (Thermo Nicolet) FT-NIR spectrometer, equipped with an integrating sphere and a spinning cup. Samples were scanned at a resolution of $8 \mathrm{~cm}^{-1}$ from $4000 \mathrm{~cm}^{-1}$ to $1000 \mathrm{~cm}^{-1}$ and 64 scans for each sample were averaged. Spectra were split in three subsets corresponding to each soil type.

\section{Chemometrics}

All spectra of each subset were scatter-corrected by extended multiplicative scatter correction (EMSC) $)^{14,15}$ using the EMSC toolbox (ver. 1.1; Eigenvector Research Inc., USA) using the spectrum of untreated soil as reference, a second 
Table 3. Parameters optimised using the mineralisation model. $\mathrm{C}_{\mathrm{L}}=$ the potentially mineralisable labile carbon pool; $\mathrm{C}_{\mathrm{S}}=$ the potentially mineralisable resistant carbon pool; $\mathrm{K}_{\mathrm{L}}=$ decomposition constant of the labile pool, slurry dependent; $\mathrm{K}_{\mathrm{S}}=$ decomposition constant of the stable pool, soil dependent.

\begin{tabular}{|c|c|c|c|c|c|c|c|c|c|c|}
\hline \multirow{2}{*}{ Soil } & \multicolumn{3}{|c|}{$\mathrm{C}_{\mathrm{L}}$ (mg kg $\mathrm{m}^{-1}$ soil) } & \multicolumn{3}{|c|}{$\mathrm{C}_{\mathrm{S}}$ (mg kg ${ }^{-1}$ soil) } & \multirow{2}{*}{\multicolumn{2}{|c|}{$\mathrm{k}_{\mathrm{L}}\left(\right.$ day $\left.^{-1}\right)$}} & \multirow{2}{*}{\multicolumn{2}{|c|}{$\mathrm{k}_{\mathrm{S}}\left(\right.$ day $\left.^{-1}\right)$}} \\
\hline & 1 & 2 & 3 & 1 & 2 & 3 & & & & \\
\hline Soil management & & & & & & & \multicolumn{2}{|c|}{ Sludge } & \multicolumn{2}{|c|}{ Soil } \\
\hline Sludge 1 & 412 & 372 & 331 & 1381 & 1066 & 1070 & 1 & 0.1762 & 1 & 0.0063 \\
\hline Sludge 2 & 370 & 457 & 388 & 1575 & 1343 & 1505 & 2 & 0.0895 & 2 & 0.0059 \\
\hline Sludge 3 & 585 & 533 & 488 & 1592 & 1167 & 1203 & 3 & 0.1327 & 3 & 0.0082 \\
\hline Sludge 4 & 294 & 229 & 215 & 1138 & 1028 & 953 & 4 & 0.3823 & & \\
\hline Sludge 5 & 529 & 424 & 442 & 1265 & 1233 & 1084 & 5 & 0.1462 & & \\
\hline Not manured & 0 & 0 & 0 & 842 & 762 & 745 & & & & \\
\hline
\end{tabular}

order polynomial for model background and a classical least squares (CLS) fitting approach. Spectra of pure analytes were not used nor were spectra of interferents filtered out. No further pre-treatments were carried out in the subsequent data processing in order to maximise the spectral comprehension of the calibration models.

The high repeatability obtained for C loss measurements allowed the use of the mean spectrum of three replicates of each treatment for C NIR prediction; these mean spectra were also used for PCA analyses. Conversely, in the case of $\mathrm{N}$ measurements, the high variability between replicates required the use of individual spectra of replicates.

PCA and PLS analyses were carried out using PLS_toolbox (ver. 4.1; Eigenvector Research Inc., USA).

A six-block cross-validation procedure was adopted for the validation of NIR results, excluding an entire soil management lunmanured soil or soil plus sludge) each time. This procedure was applied in order to avoid overfitting as much as possible. Furthermore, this validation method ensured a robust modelling of the spectral features common to all slurries and soil organic matter.

\section{Results and discussion}

Figure 1 shows the scatter-corrected spectra of all the experimental units. The spectra arising from the soil with the highest clay content (soil 3) showed the highest offset values and also the highest absorptions. As highlighted in Figure 2, in which the standard deviation spectra of the three incubated soils are shown, the main variations in the signals were due to $\mathrm{CH}$ stretching and deformations $\left(4286 \mathrm{~cm}^{-1}\right)$, $\mathrm{CH}$ bending $I$ overtone $\left(4327 \mathrm{~cm}^{-1}\right), \mathrm{CH}-\mathrm{CO}$ combinations $\left(4537 \mathrm{~cm}^{-1}\right)$, absorptions arising from hydration bound water $\left(5128,5173\right.$ and $\left.5165 \mathrm{~cm}^{-1}\right)$ and $\mathrm{OH}$ and $\mathrm{NH}$ overtones $(6840$ and $6859 \mathrm{~cm}^{-1}$ ).

\section{PCA analysis}

PCA was performed on each soil separately.

Analysing the structure of spectral data for each soil type by PCA, a common behaviour between the treatments relating to the progress of incubation was found. The time plots of scores for each type of soil (Figure 3) show that the trends are, independently, very similar to the manure applied. Using PC1, this information was clearly evident for soil 1 [Figure 3(a)] and 2 [Figure 3(b)] and it was also still recognisable in soil 3 [Figure 3(c)], even if it showed a more complex shape.

Considering the PC2 or PC3 time plots, also reported in Figure 3, PCA was able to discriminate between the manured and unmanured treatments at time 0, particularly along PC3 for soil 1 and along PC2 for soil 2, even if these were less evident. In all three soils, the maximum spectral variation, recognisable on PC1 scores, as expected, did not occur between manured and unmanured treatments at time 0 , but occurred after the incorporation of cattle sludge, when microbial activity took place, corresponding to two days after incorporation for soil 1 and later during the incubation period for soils 2 and 3 .

The complexity of the behaviour in soil 3 reveals the prominent role of the clay-organic matter interaction in the spectral response.

\section{NIR predictions of carbon content}

The calibration and validation results for the estimation, carried out by NIR, of total organic $C$ and of $C$ concentration in the different modelled pools are reported in Table 4.

In particular, total carbon $\left(\mathrm{C}_{\text {total }}\right)$ remaining at time $t$, defined as the sum of soil $\mathrm{C}$ at time zero $\left(\mathrm{C}_{\text {Soil }}\right)$ and of slurry carbon $\left(\mathrm{C}_{\text {Sludge }}\right)$ at time zero minus respired carbon $\left(\mathrm{C}_{\mathrm{CO}_{2}}\right)$ at time $t$ :

$$
C_{\text {total }}(t)=C_{\text {Soil }}+C_{\text {Sludge }}-C_{\mathrm{CO}_{2}}(t)
$$

was quite well predicted $\left(r_{\mathrm{val}}^{2}=0.76,0.90\right.$ and 0.80 for the three soils).

Figure 4 shows the scatter plots of the six block crossvalidation results for the three soils.

Best prediction results were obtained for soil 2: in this case, the mineralisation in the treatment without sludge was also well predicted, as shown in Figure 4(b).

Even if the amount of mineralised carbon was between 200 and $2100 \mathrm{mg} \mathrm{kg}^{-1}$, representing at most $14 \%$ of total C in soil and less than $0.25 \%$ of dry soil, a good spectroscopic discrimi- 


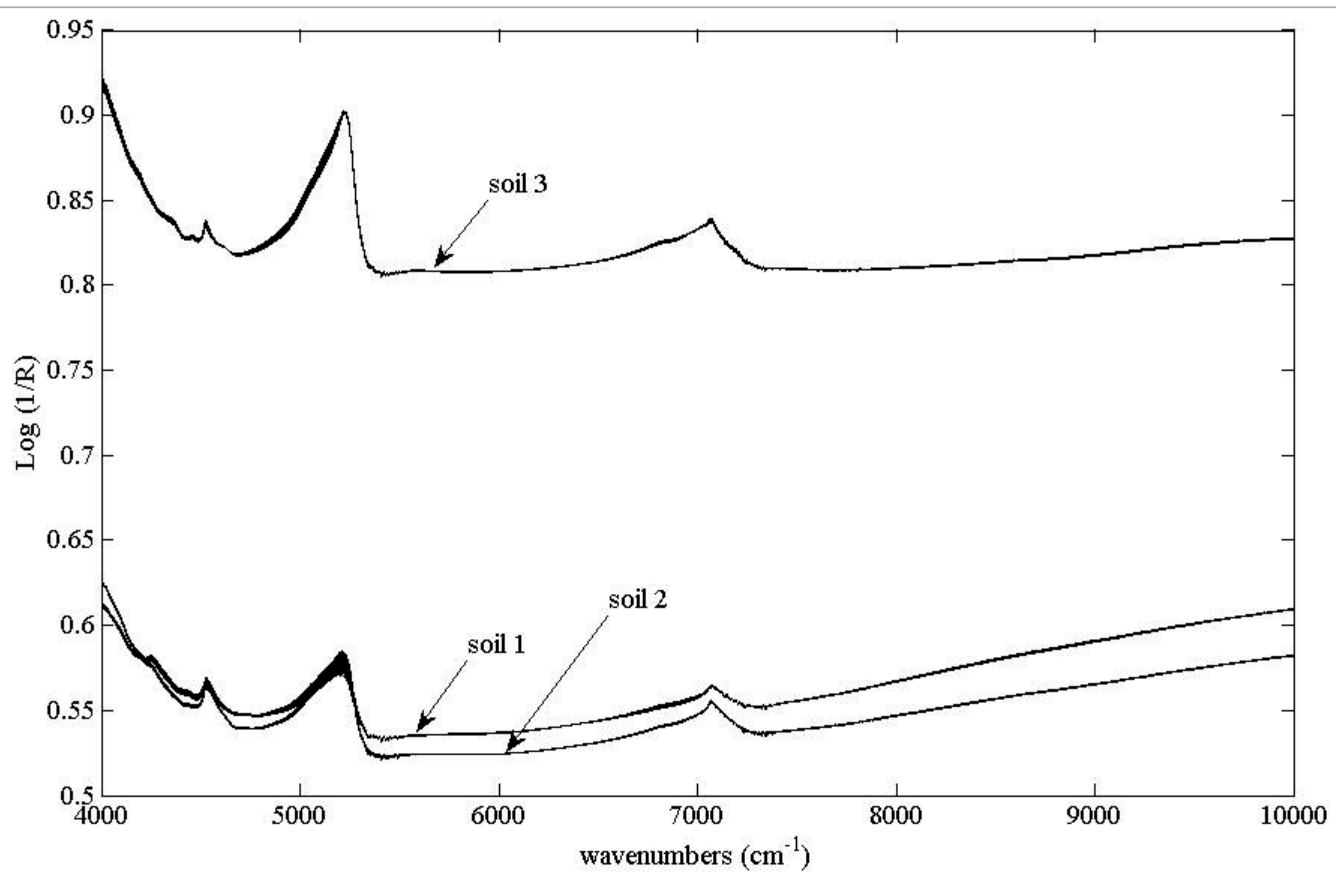

Figure 1. Extended multiplicative scatter corrected spectra of the three soil sets.

nation between the beginning and the end of sludge mineralisation was obtained.

A two-pool empirical model was found to be an adequate approach to the data of the incubation experiments in an effort to split organic matter into more homogeneous fractions: this approach was useful for a better understanding of the early mineralisation phase, in particular when all the tested sludges may have initially withdrawn mineral $\mathrm{N}$ from the soil. ${ }^{15}$ Figure 5 shows two illustrative runs of the mineralisation model for soil 1 without sludge [Figure 5(a)] and with sludge 1 [Figure $5(b)$ ]. In both cases, the $C_{S}$ pool does not completely mineralise during the incubation experiment and a fraction of the pool is still present after 180 days of incubation while the $C_{\perp}$ pool is fully respired. This behaviour

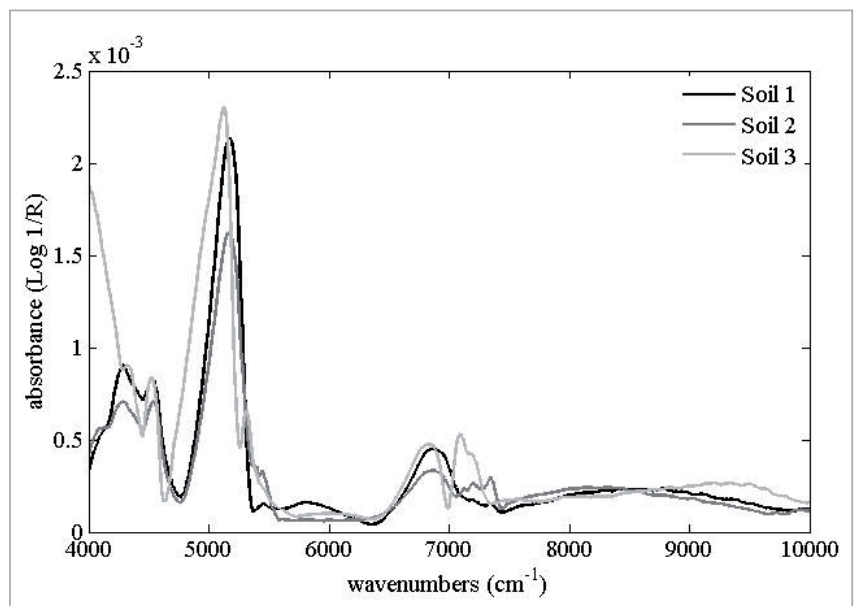

Figure 2. Absorbance spectra of the three soil sets. was found in all 18 treatments where, in general, the labile fraction $\left(C_{L}\right)$ disappeared between 10 and 40 days of incubation, whereas about $20 \%$ of residual $C$ from $C_{S}$ pools was still present after 180 days.

The simultaneous prediction of $C_{S}(t)$ and $C_{L}(t)$ was obtained by applying a PLS2 calibration: the main advantage of this approach is to build up a more robust model even if it has a lower accuracy.

The results reported in Table 4 show that the predictions of the $\mathrm{C}_{\mathrm{S}}$ pool were always good, with RPD values higher than 2.00.

The time-plots of the six-block cross-validation, shown in Figure 6, demonstrate that NIR can discriminate situations when $C_{L}$ is still present or has been completely mineralised.

The sum of $C_{S}$ and $C_{L}$ pools $\left(C_{\text {min }}\right)$ gives the amount of potentially mineralisable carbon in the soil.

The $\mathrm{C}_{\min }$ amount over incubation was calculated as:

$$
\mathrm{C}_{\text {min }}(t)=\mathrm{C}_{\mathrm{S}}+\mathrm{C}_{\mathrm{L}}-\mathrm{C}_{\mathrm{CO}_{2}}(t)
$$

The $C_{\text {min }}$ prediction, excluding $C_{\mid}$pools from the calibration model, gave better results than those of $C_{\text {tot }}$ in terms of RMSECV, RER and RPD, even if the range and the standard deviation of $C_{\min }$ were always smaller than those of $C_{\text {tot. }}$. The only exception was obtained in the case of the RER value for soil 2, as pointed out in Table 4 and in Figure 7, where the six-block cross-validation scatter plots for the three soils are shown. This demonstrated that a mineralisation model, giving a first approximation of the amount of chemically-similar $\mathrm{C}$ fractions, can be useful in helping to unravel soil organic matter composition.

The squared beta coefficients of the PLS $C_{\text {min }}$ calibration are shown in Figure 8. 

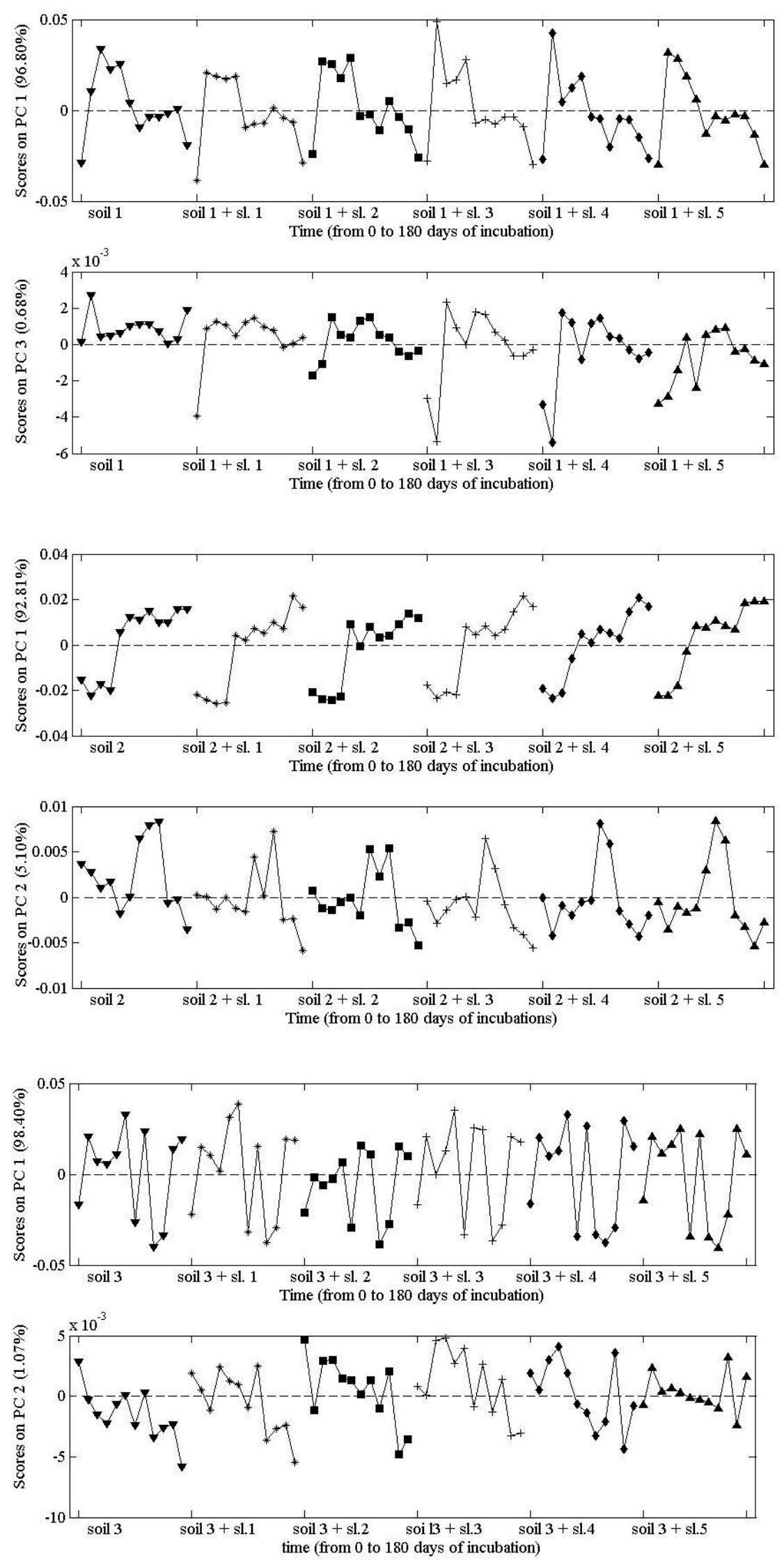

Figure 3. Time plots of the most influential PCA scores of the three soil sets. 
Table 4. Statistical parameters obtained for the calibration of $\mathrm{C}_{\text {total }}, \mathrm{C}_{\mathrm{L}}, \mathrm{C}_{\mathrm{S}}$ and $\mathrm{C}_{\min }$ in calibration and six block cross-validation. $\mathrm{C}_{\text {total }}=$ total carbon in soils; $C_{L}=$ the potentially mineralisable labile carbon pool; $C_{S}=$ the potentially mineralisable resistant carbon pool; $C_{\text {min }}=$ potentially mineralisable carbon.

\begin{tabular}{|c|c|c|c|c|c|c|c|c|c|c|c|c|}
\hline & \multicolumn{4}{|c|}{ Soil 1} & \multicolumn{4}{|c|}{ Soil 2} & \multicolumn{4}{|c|}{ Soil 3} \\
\hline Parameter & $\mathrm{C}_{\text {total }}$ & $C_{L}$ & $\mathrm{C}_{\mathrm{s}}$ & $C_{\min }$ & $\mathrm{C}_{\text {total }}$ & $C_{L}$ & $\mathrm{C}_{\mathrm{S}}$ & $C_{\min }$ & $C_{\text {total }}$ & $C_{L}$ & $\mathrm{C}_{\mathrm{S}}$ & $C_{\min }$ \\
\hline N & 72 & 72 & 72 & 72 & 72 & 72 & 72 & 72 & 72 & 72 & 72 & 72 \\
\hline Min & 13320 & 0 & 200 & 200 & 14310 & 0 & 207 & 207 & 17430 & 0 & 148 & 148 \\
\hline Max & 15600 & 570 & 1535 & 2015 & 16830 & 520 & 1287 & 1725 & 19990 & 480 & 1507 & 1885 \\
\hline Std dev & 544 & 143 & 344 & 449 & 576 & 134 & 267 & 468 & 590 & 125 & 328 & 420 \\
\hline Range & 2280 & 570 & 1335 & 1905 & 2520 & 520 & 1080 & 1518 & 2560 & 480 & 1359 & 1737 \\
\hline Method & PLS & PLS2 & PLS2 & PLS & PLS & PLS2 & PLS2 & PLS & PLS & PLS2 & PLS2 & PLS \\
\hline Factors & 7 & 7 & 7 & 7 & 8 & 8 & 8 & 6 & 7 & 8 & 8 & 8 \\
\hline RMSEC & 169 & 62 & 139 & 85 & 108 & 59 & 73 & 106 & 168 & 60 & 70 & 113 \\
\hline RMSECV & 269 & 86 & 164 & 200 & 184 & 93 & 105 & 147 & 261 & 86 & 120 & 176 \\
\hline$r_{\text {val }}^{2}$ & 0.76 & 0.68 & 0.77 & 0.81 & 0.90 & 0.63 & 0.85 & 0.84 & 0.80 & 0.57 & 0.86 & 0.83 \\
\hline$R P D$ & 2.02 & 1.67 & 2.10 & 2.24 & 3.13 & 1.44 & 2.54 & 3.18 & 2.26 & 1.45 & 2.73 & 2.39 \\
\hline RER & 8.48 & 6.63 & 8.14 & 9.53 & 13.70 & 5.59 & 10.29 & 11.73 & 9.81 & 5.58 & 11.33 & 10.71 \\
\hline
\end{tabular}
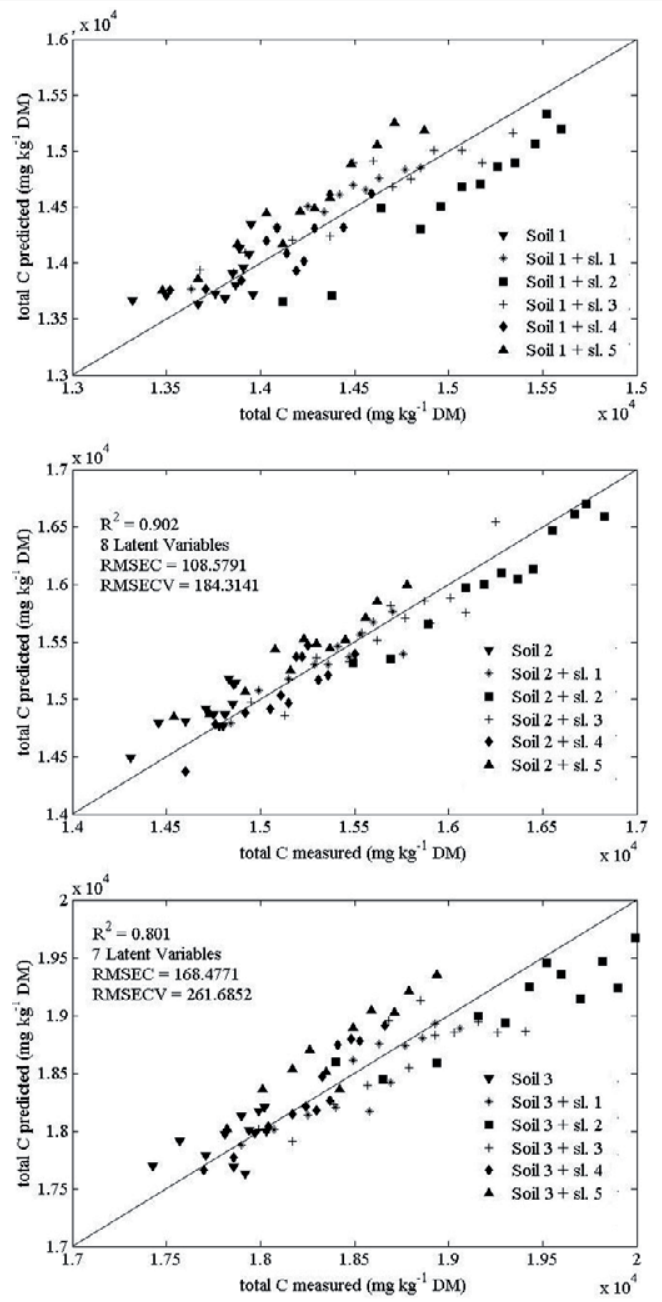

Figure 4. Six blocks cross-validation scatter plot of PLS $\mathrm{C}_{\text {total }}$ predicted vs $\mathrm{C}_{\text {total }}$ measured for the three soil sets.

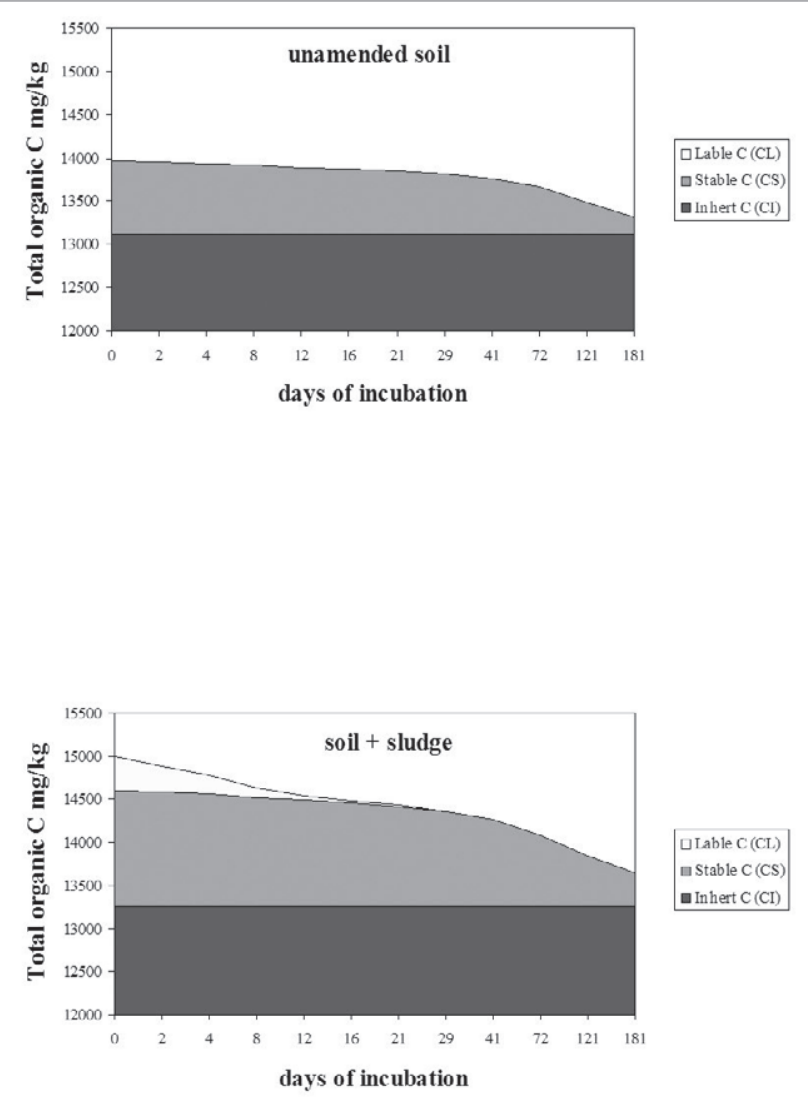

Figure 5. Mineralisation model-fitted concentration of the $\mathrm{C}$ pools during incubation experiments for soil 1 (top) and soil $1+$ sludge 1 (bottom). 

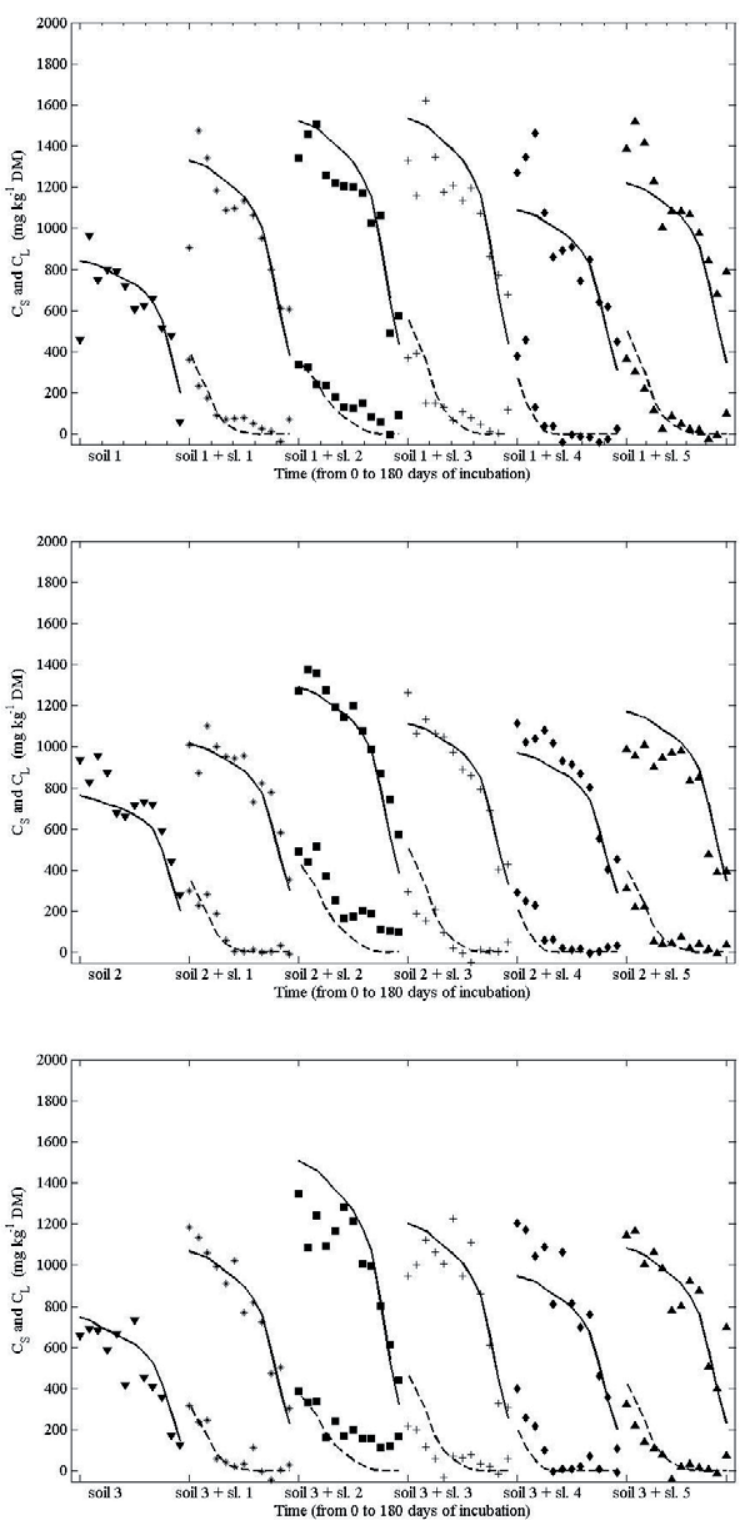

Figure 6. Time plot of six blocks cross-validation NIR prediction of $\mathrm{C}_{\mathrm{L}}$ ( potentially mineralisable labile carbon pool) and $\mathrm{C}_{\mathrm{S}}$ (potentially mineralisable resistant carbon pool) concentrations (dots) against mineralisation model values for $\mathrm{C}_{\mathrm{L}}$ (dotted lines) and $\mathrm{C}_{\mathrm{s}}$ (continuous lines) for the three soil sets.

The regressors, although representative of the mineralisation of the same five sludges, reveal different behaviours among soils especially in the region from $4500 \mathrm{~cm}^{-1}$ to $5500 \mathrm{~cm}^{-1}$. These results highlighted the active role of interactions between clay and organic matter in the spectroscopic response of soil mineralisation.

\section{NIR calibration of mineral $\mathrm{N}$ content}

Soil mineral nitrogen includes nitrate $\mathrm{N}$ and ammonium $\mathrm{N}$. The $\mathrm{N}-\mathrm{H}$ bond, with its strong anharmonicity, gives rise to strong NIR signals whereas the $\mathrm{N}-\mathrm{O}$ bond of nitrate, occurring
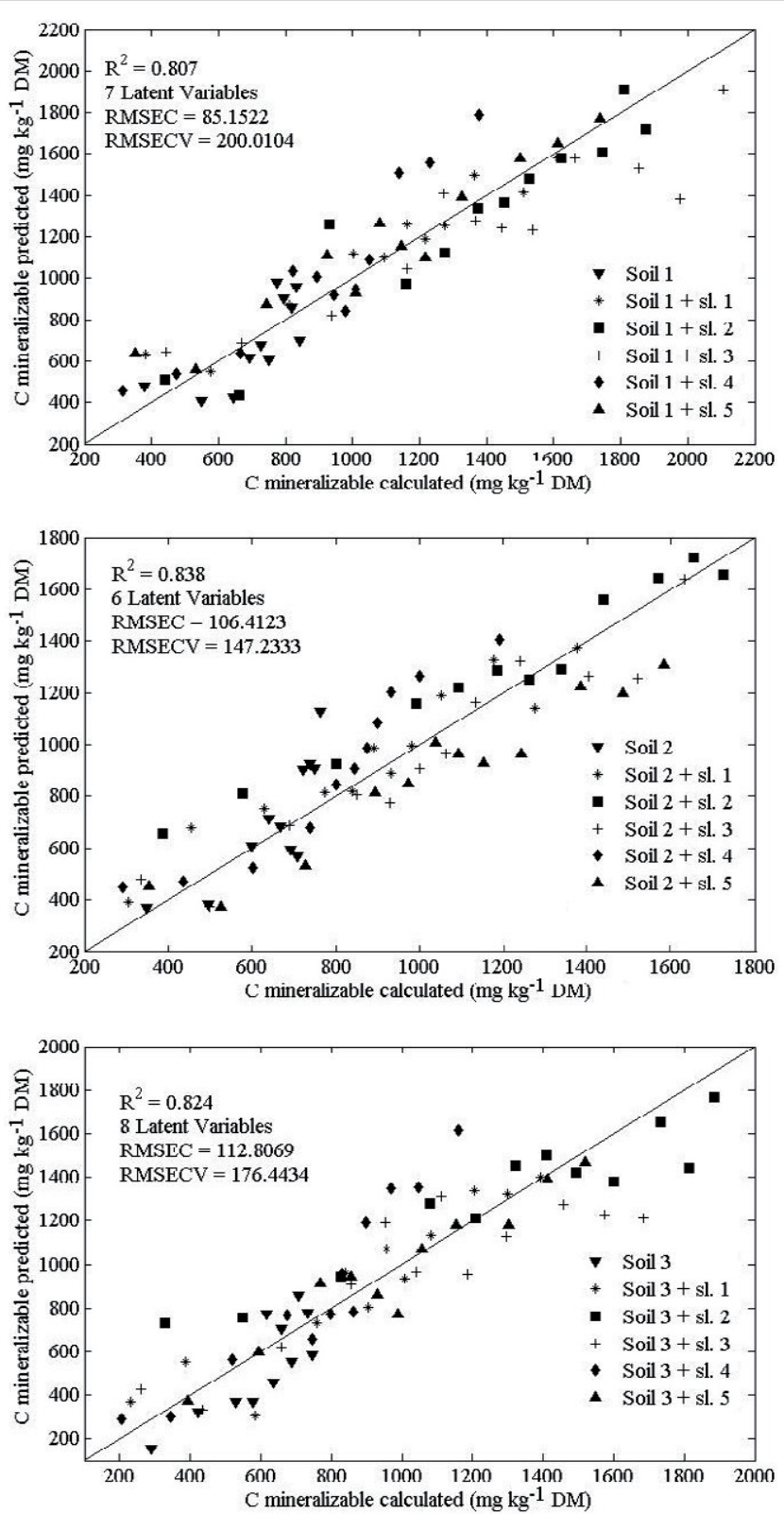

Figure 7. Six blocks cross-validation scatter plot of PLS $\mathrm{C}_{\min }$ (potentially mineralisable carbon) predicted vs $\mathrm{C}_{\min }$ calculated for the three soil sets.

between two atoms of similar mass, is less anharmonic and then has weaker NIR absorptions.

According to these general rules, in our experiments ammonium release by sludge in soil was demonstrated to be predictable by NIR while nitric N prediction was very poor (data not shown), especially for unmanured treatments. Similar results were observed by Reeves and Van Kessel ${ }^{6}$ in calibrating control and non-control samples together. The nitric $\mathrm{N}$ predictions obtained calibrating only manured treatments could not be accounted for because, in our experiments, nitrate concentrations in these treatments were very collinear with $\mathrm{C}_{\mathrm{CO}_{2}}$. 

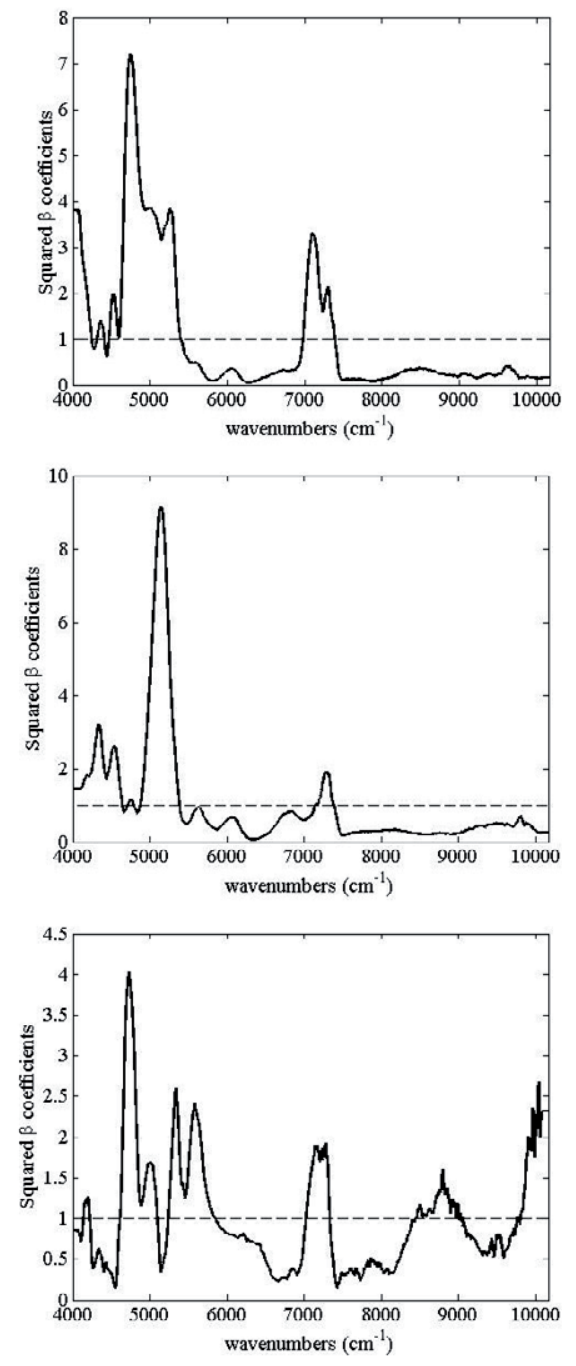

Figure 8. Squared beta coefficient of $\mathrm{C}_{\min }$ (potentially mineralisable carbon) calibrations for soil 1 (top), soil 2, (middle) and soil 3 (bottom).
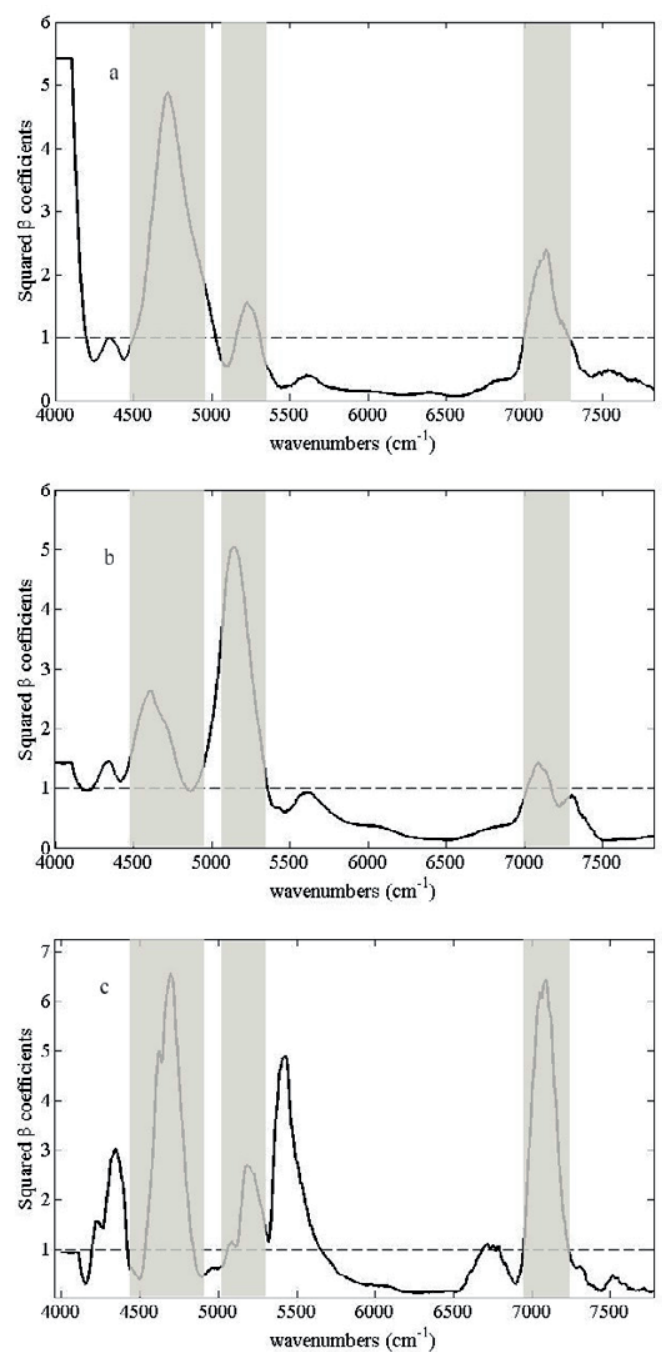

Figure 9. Squared beta coefficients of ammonium $\mathrm{N}$ calibrations for soil 1 (top), soil 2 (middle) and soil 3 (bottom); Shaded regions indicate $\mathrm{N}-\mathrm{H}$ bond signals.

Table 5. Statistical parameters obtained for the calibration of ammonium $\mathrm{N}$ in calibration and six-block validation.

\begin{tabular}{|c|c|c|c|}
\hline & \multicolumn{3}{|c|}{ Ammonium $\mathrm{N}\left(\mathrm{mg} \mathrm{kg}^{-1}\right)$} \\
\hline & Soil 1 & Soil 2 & Soil 3 \\
\hline N & 216 & 216 & 216 \\
\hline Min & 1 & 0 & 1 \\
\hline Max & 77 & 52 & 65 \\
\hline Std dev. & 16 & 9 & 13 \\
\hline Range & 76 & 52 & 64 \\
\hline Method & PLS & PLS & PLS \\
\hline Factors & 10 & 6 & 8 \\
\hline RMSEC & 5 & 5 & 4 \\
\hline RMSECV & 6 & 5 & 6 \\
\hline$r_{\text {val }}^{2}$ & 0.87 & 0.64 & 0.75 \\
\hline RPD & 2.74 & 1.66 & 2.27 \\
\hline RER & 13.42 & 9.41 & 11.18 \\
\hline
\end{tabular}


The cross-validation results for ammonium $\mathrm{N}$ are reported in Table 5. The squared beta coefficients of PLS for ammonium $\mathrm{N}$ are reported in Figure 9. There are three bands common to all three soils truly due to $\mathrm{N}-\mathrm{H}$ bonds: $\mathrm{N}-\mathrm{H}$ bending II overtone around $4690 \mathrm{~cm}^{-1}, \mathrm{~N}-\mathrm{H}$ stretching III overtone at $5180 \mathrm{~cm}^{-1}$ and $\mathrm{N}-\mathrm{H}$ stretching $I$ overtone at $7110 \mathrm{~cm}^{-1}$. In this case, the beta squared coefficients obtained for the three soils are more influenced by the chemical structure of the analyte than by the analyte interactions with clay as in the case of organic carbon.

\section{Conclusions}

NIR spectroscopy proved to be a useful tool to follow the mineralisation process of cattle slurries in soil, even when only a minor part of total soil carbon (in this case from $4 \%$ to $14 \%$ ) was supplied.

In fact, as is well explained in Dahm and Dahm, ${ }^{17}$ reflectance spectra of a mixture of particle sizes looks more like the small particles than the big particles; therefore, the smallest soil particles are the most spectroscopically-active, namely clay and clay-absorbed organic matter: this can explain the surprising sensitivity of soil NIR measurements. ${ }^{18}$

It is possible to estimate that the amount of mineralisation observed during the 180 days of this laboratory incubation under optimal temperature conditions corresponds to about two years under field conditions (with limiting temperature and soil water content) in northern Italy. Over a period of 180 days, the control treatments mineralised about $4 \%$ of native soil organic $C$. As it is normally assumed that in field conditions about $2 \%$ of organic $C$ is mineralised annually, ${ }^{19}$ the sixmonth incubation corresponds to about two years of real soil temperature and humidity conditions.

Because of the variability of both soil temperature and soil water content, depending on years and site, the NIR technique can be very useful in order to know if the added sludge is fully mineralised or not. The behaviour of soil spectra observed during mineralisation by PCA analysis needs to be confirmed with in-field experiments in which liquid cattle manures are not homogenised.

Nitrogen mineralisation can be directly monitored by NIR spectroscopy by only considering the ammonium $\mathrm{N}$ concentration. On the basis of this information, side dress application of mineral $\mathrm{N}$ fertilisers can be more appropriate.

NIR predictive ability can be improved by using mineralisation models able to unravel soil organic matter complexity into homogeneous pools and to account for the behaviour of unmanured treatments in a single calibration. On the other hand, when data on the beginning and end of mineralisation are available, NIR could be used to optimise the mineralisation models by RMSECV minimisation as proposed by Hartmann. ${ }^{4}$

The interaction between clay and organic matter is identified as the limiting factor that must be investigated for the extension of a single calibration model over different types of soil using data obtained from only three soils and for deve- loping in-field applications, whereas this task appears more feasible for ammonium calibrations. To overcome this problem, the robustness of the calibrations should be improved, finding a suitable chemometric way to reduce or model this influence. It is necessary to build up a large number of incubation assays on different soils in order to develop robust multi-soil calibrations for different soil groups.

\section{References}

1. M.J. Swift, O.W. Heal and J.M. Anderson, Decomposition in terrestrial ecosystems. Blackwell Publishing, Oxford, UK (1979).

2. K.H. Tan, Principles of soil chemistry, Third Edition. Marcel Dekker Inc., New York, USA, pp. 431-456 (1998).

3. G. Schroth, B. Vanlauwe and J. Lehmann, "Soil organic matter" in Trees, crops and soil fertility, Ed by G. Schroth and F.L. Sinclair. CABI Publishing, Wallington, UK, pp. 77-92 (2003).

4. H.P. Hartmann and T. Appel, "Calibration of near infrared spectra for measuring decomposing cellulose and green manure in soils", Soil Biol. Biochem. 30, 887-897 (2006). doi: $10.1016 /$ j.soilbio.2005.08.005

5. K. Paustian, G.I. Agren and E. Bosatta, "Modelling litter quality effects on decomposition and soil organic matter dynamics", in Driven by nature: plant litter quality and decomposition, Ed by G. Cadish and K.E. Giller. CAB International, Wallingford, UK, pp. 313-335 (1997).

6. J.B. Reeves and J.S. Van Kassel, "Investigations into near infrared analysis as an alternative to traditional procedures in manure nitrogen and carbon mineralisation studies", J. Near Infrared Spectrosc. 7, 195-212 (1999).

7. D.F. Malley, P.D. Martin and E. Ben Dor, "Application in analysis of soils" in Near infrared spectroscopy in agriculture, Ed by C.A. Roberts, J. Workman Jr and J.B. Reeves, III. American Society of Agronomy Inc., Crop Science Society of America Inc. and Soil Science Society of America Inc. Publishers, Madison, Wisconsin, USA, pp. 729-784 (2004).

8. D. Gillon and J.F. David, "The use of near infrared reflectance spectroscopy to study chemical changes in the leaf litter consumed by saprophagous invertebrates", Soil Biol. Biochem. 33 , 2159-2161 (2001). doi: 10.1016/S0038-0717(01)00139-0

9. B. Ludwig, P.K. Khanna, J. Bauhus and P. Hopmans, "Near infrared spectroscopy of forest soils to determine chemical and biological properties related to soil sustainability", Forest Ecol. Manag. 171, 121-132 (2002). doi: 10.1016/S03781127(02)00467-X

10. M. Chodak, B. Ludwig, P. Khanna and F. Beese, "Use of near infrared spectroscopy to determine biological and chemical characteristics of organic layers under spruce and beech stands", J. Plant Nutr. Sci. 165, 27-33 (2002). doi: 10.1002/15222624(200202)165:1<27::AID-JPLN27>3.0.CO;2-A

11. G. De Ferrari, P. Marino Gallina, G. Cabassi, L. Bechini and T. Maggiore, "Near infrared spectral analysis of cattle slurries from Lombardy (Northern Italy) breeding farms", in Near infrared spectroscopy: Proceedings of the $12^{\text {th }}$ international conference, Ed by G.R. Burling-Claridge, S.E. Holroyd and R.M.W. 
Sumner. New Zealand Near Infrared Spectroscopy Society Inc., Hamilton, New Zealand, pp. 505-513 (2007).

12. L. Thuriès, M.C. Larre-Larrouy and M. Pansu, "Evaluation of three incubation designs for mineralization kinetics of organic materials in soil", Commun. Soil Sci. Plant Anal. 31, 289-304 (2000).

13. D.S. Jenkinson, "Studies on the decomposition of plant material in soil. V. The effects of plant cover and soil type on the loss of carbon from ${ }^{14} \mathrm{C}$-labelled ryegrass decomposing under field conditions", J. Soil Sci. 28, 424-434 (1977).

14. H. Martens, J.P. Nielsen and S.B. Engelsen, "Light scattering and light absorbance separated by extended multiplicative signal correction. application to near-infrared transmission analysis of powder mixtures", Anal. Chem. 75, 394-404 (2003). doi: $\underline{10.1021 / a c 020194 \mathrm{~W}}$

15. N.B. Gallagher, T.A. Blake and P.L. Gassman, "Application of extended inverse scatter correction to mid-infrared reflectance spectra of soil", J. Chemometr. 19, 271-281 (2006). doi: $\underline{10.1002 / \mathrm{cem} .929}$
16. B. Stenberg, T.M. Henriksen, S. Bruun, A. Korsaeth, L.S. Jensen, T.A. Breland, E. Nordkvist, F. Palmason, T. Salo, J. Gudmundsson and M. Esala, "Description of plant material quality by near infrared spectroscopy for prediction of carbon and nitrogen mineralisation in agricultural soils", in Near infrared spectroscopy: Proceedings of the $12^{\text {th }}$ international conference, Ed by G.R. Burling-Claridge, S.E. Holroyd and R.M.W. Sumner. New Zealand Near Infrared Spectroscopy Society Inc., Hamilton, New Zealand, pp. 505-513 (2007).

17. D.J. Dahm and K.D. Dahm, Interpreting diffuse reflectance and transmittance. IM Publications, Chichester, UK (2007).

18. J.M. Olinger, P.R. Griffiths and T. Burger, "Theory of diffuse reflection in the NIR region" in Handbook of near-infrared analysis, Ed by D.A. Burns and E.W. Ciurkzak. Marcel Dekker Inc., New York, USA, pp. 19-52 (2001).

19. L. Giardini, General agronomy (in Italian). Patron editore, Bologna, Italy, pp. 359-398 (1992). 